\title{
First record of the powdery mildew fungus Erysiphe polygoni on the introduced coral vine Antigonon leptopus (Polygonaceae) in Taiwan
}

\author{
Wang $C^{1}$, Yeh $Y^{2}$, Lin $L^{3}$ and Kirschner $\mathbf{R}^{4}$ \\ ${ }^{1}$ The Experimental Forest, College of Bioresources and Agriculture, National Taiwan University, Jhushan Township, \\ Nantou, Taiwan \\ ${ }^{2}$ Department of Biomedical Sciences \& Engineering, National Central University, Taoyuan, Taiwan \\ ${ }^{3}$ Department of Cultural Heritage Conservation, National Yunlin University of Science and Technology, Yunlin, \\ Taiwan \\ ${ }^{4}$ School of Forestry \& Resource Conservation, National Taiwan University, Taipei, Taiwan
}

Wang CT, Yeh YW, Lin LD, Kirschner R 2019 - First record of the powdery mildew fungus Erysiphe polygoni on the introduced coral vine Antigonon leptopus (Polygonaceae) in Taiwan. Plant Pathology \& Quarantine 9(1), 160-165, Doi 10.5943/ppq/9/1/14

\begin{abstract}
Antigonon leptopus has been naturalized in Taiwan for about 100 years, but hitherto no fungal species was recorded on this plant in Taiwan. A powdery mildew fungus collected on $A$. leptopus in central and northern Taiwan was identified as Erysiphe polygoni based on internal transcribed spacer sequence comparison and morphology of the anamorph.
\end{abstract}

Key words - Erysiphaceae - ITS - new host record - pathogenic Ascomycota - pest insects

\section{Introduction}

Antigonon leptopus Hook. \& Arn. (Polygonaceae) is a liana native to the neotropical region (Mexico) (Burke \& DiTommaso 2011). After introduction as ornamental in tropical countries worldwide and particularly in islands, the plant became invasive due to its high clonal reproduction from tuberous roots (Burke \& DiTommaso 2011). The species was first recorded as naturalized in Taiwan in 1916 (Wu et al. 2010). Hitherto several polyphagous insects have been recorded on this plant in Taiwan, such as the moth Lymantria xylina Swinhoe (Erebidae, Lepidoptera; Yeh et al. 2007), the scale insect Parasaisettia nigra (Nietner) (Coccidae, Hemiptera; Wong et al. 1999), and the white fly Aleurodiscus dispersus Russell (Aleyrodidae, Hemiptera; Ko 2016), but no fungi. A powdery mildew was discovered on leaves of this plant in central and northern Taiwan which had not been recorded for this host in Taiwan previously (Kuo 1998, Farr \& Rossman 2019).

\section{Materials \& Methods}

Specimens were collected and kept in a refrigerator until processing. For microscopy, fresh specimens were mounted in $10 \% \mathrm{KOH}$; sizes were measured at $1000 \times$ magnification and presented as mean value \pm standard deviation of 30 measurements with extreme values in brackets. Dried specimens were deposited at the National Museum of Natural Science, Taichung (TNM) and the Department of Plant Pathology and Microbiology, National Taiwan University Herbarium, Taipei, Taiwan (PPMH). DNA was isolated from freshly collected conidia, and the internal transcribed spacer (ITS) region of the ribosomal RNA genes was amplified, sequenced, and edited as in Wei \& 
Kirschner (2017). The ITS sequence was used for BLAST searches and deposited in GenBank (accession number MK685172). Alignments were based on sequences selected from BLAST search results and Meeboon \& Takamatsu (2017) with E. convolvuli DC. as outgroup. Alignments and Maximum Likelihood analyses with 1000 bootstrap replicates were done as in Yeh et al. (2019).

\section{Results}

BLAST searches at GenBank with an ITS sequence from the material from northern Taiwan revealed the highest identity with 11 sequences from Erysiphe specimens from polygonaceous hosts (species of Fagopyrum, Muehlenbeckia and Polygonum) with 1-6 different positions (99\% identity). The majority of these sequences were published and labeled as E. polygoni, two unpublished ones, however, were wrongly labeled as E. buhrii U. Braun and E. heraclei DC. The deviating positions were not concentrated at the very ends of the aligned sequences in the BLAST hits. The second most similar sequences were three sequences of E. buhrii from Silene species (Caryophyllaceae) differing by 9 bp. Erysiphe heraclei on Apiaceae differed for at least 10 bp. In the Maximum Likelihood analysis (Fig. 1), a clade comprising ITS sequences of specimens from polygonaceous hosts was well supported. Subclades representing specimens from Antigonon and Muehlenbeckia hosts on the one hand, and Muehlenbeckia and Rumex hosts on the other were poorly supported. Sequences of E. polygoni from Polygonum species were polytomously arranged in this clade.

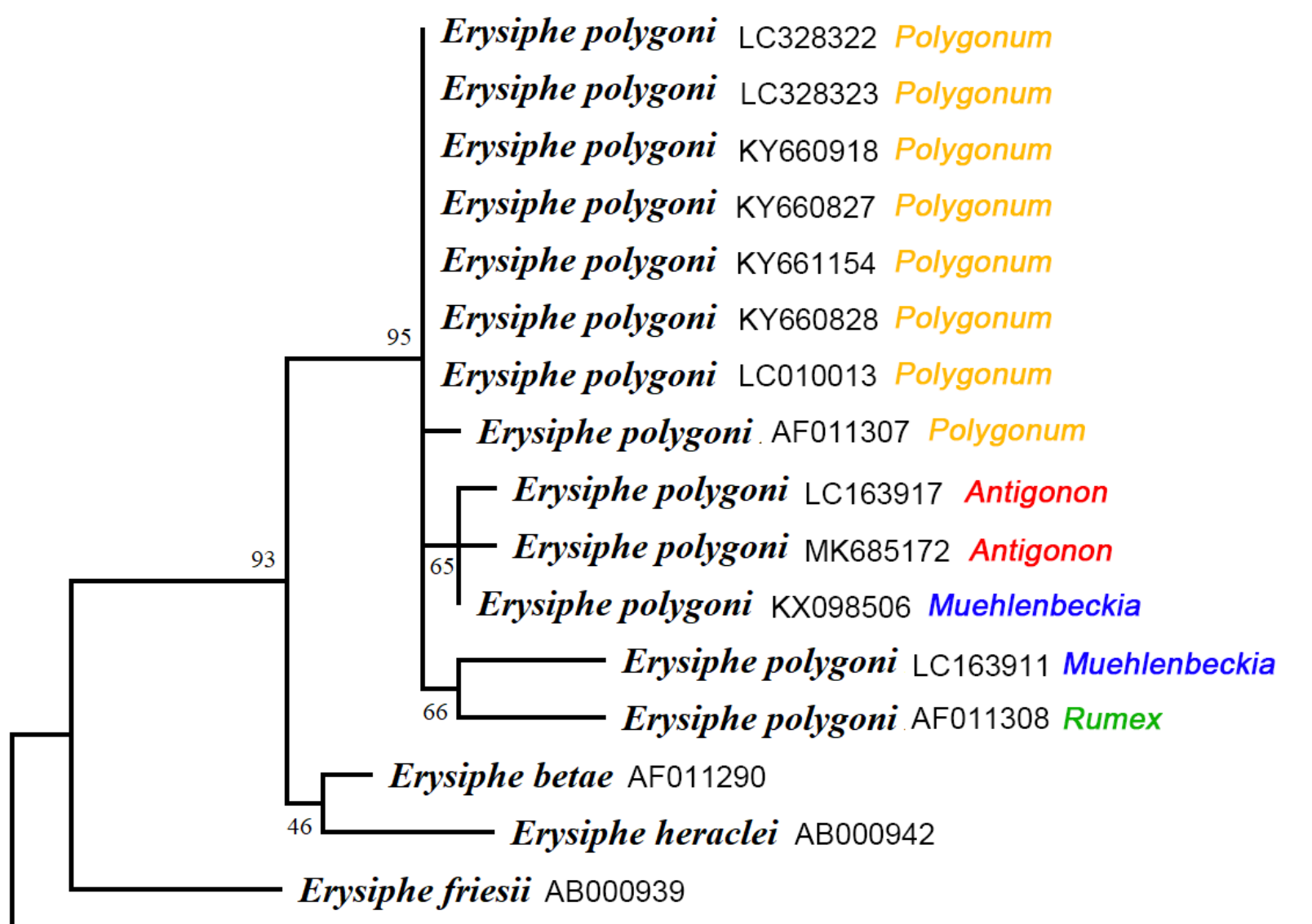

Erysiphe convolvuli AF011298

0.01

Fig. 1 - Maximum likelihood analysis of ITS sequences of Erysiphe polygoni (with host genera in color) and related powdery mildew species with their respective GenBank numbers. 
The host and morphology of the anamorph, particularly of the cylindrical conidia, conformed to the description of E. polygoni (Braun \& Cook 2012).

\section{Erysiphe polygoni DC.}

Figs 2, 3

Colonies mainly on mature green leaves, amphigenous, forming effuse white powdery patches, confluent. Older infected leaves showing evenly yellow chlorosis. Hyphae 3-8 $\mu \mathrm{m}$ wide, smooth to very finely verruculose. Hyphael appressoria nipple-shaped or lobed, solitary or in opposite pairs. Conidiophores arising from upper side of hyphal mother cell, finely verruculose, $(62-) 99-139(-165) \times(6-) 7-9(-10) \mu \mathrm{m}(\mathrm{n}=30)$. Foot cell cylindrical, straight, only exceptionally with a slight bent at the base, basal septum at the same level as upper surface of hyphal mother cell or raised distally for up to $12 \mu \mathrm{m},(26-) 48-75(-90) \times 6-8(-9) \mu \mathrm{m}(\mathrm{n}=30)$, followed by $1-3$ shorter cells. Conidia solitary, without fibrosin bodies, with fine longitudinal striation, secondary conidia cylindrical, (32-)35.5-42.5(-45) × 11-13.5 $(-15) \mu \mathrm{m}(\mathrm{n}=30)$, exceptional ones with double length (ca. $65 \mu \mathrm{m}$ ), primary conidia ellipsoid-ovoid, mostly shorter and relatively wider than secondary ones, (27-)29-34(-35) × 12-15 $\mathrm{m}(\mathrm{n}=8)$. Germination at one or both ends, forming short hyphae with strongly lobed conidial appressoria, or long hyphae with nipple-shaped appressoria. Teleomorph - not found.
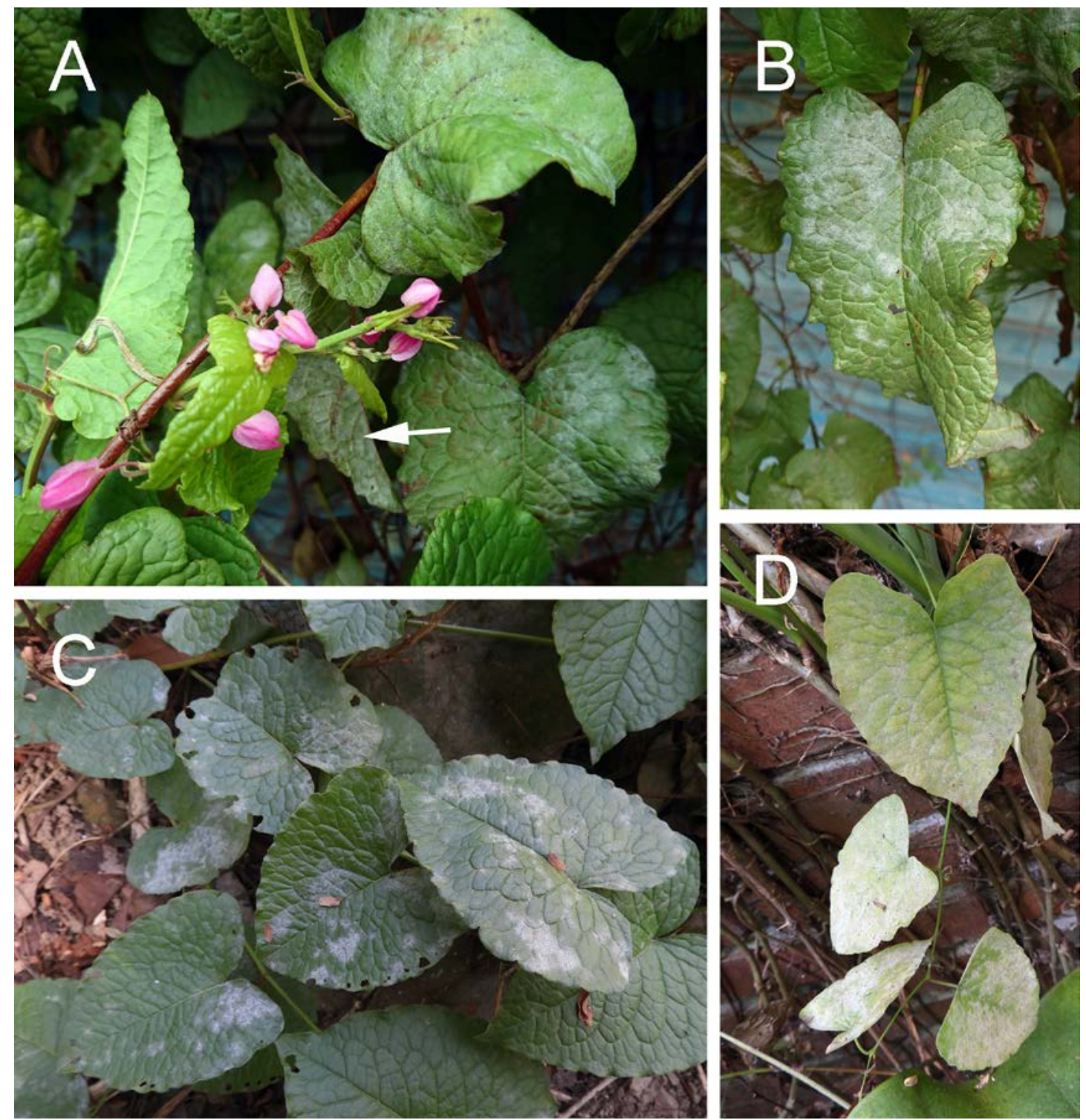

Fig. 2 - Erysiphe polygoni powdery mildew symptoms on Antigonon leptopus (A, B: R. Kirschner 4701; C, D: R. Kirschner \& C.-T. Wang 4700). Note the hypophyllous colonies of E. polygoni in A (arrow) and the chlorosis in D. 


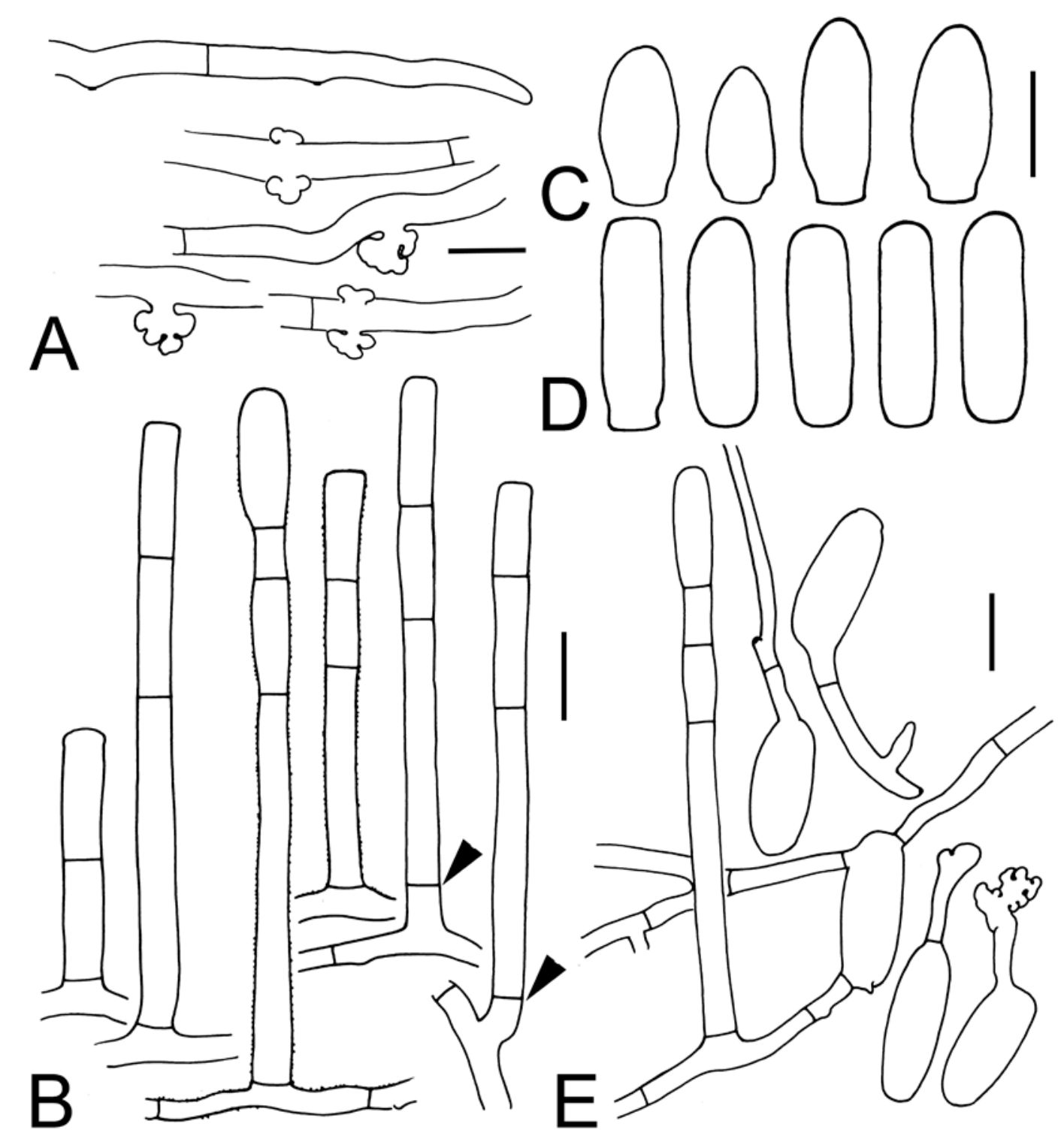

Fig. 3 - Microscopic characteristics of the anamorph of Erysiphe polygoni (R. Kirschner 4701). A. Hyphal appressoria. B. Conidiophores. Cell wall ornament indicated only in the two central ones. Note raised basal septum of foot cell in the two right conidiophores (arrowheads). C. Primary conidia. D. Secondary conidia. E. Germ tubes of conidia, the complex central one giving rise to a conidiophore, the upper right ones with nipple shaped appressoria, the lower right ones with lobed appressoria. - Scale bars $=20 \mu \mathrm{m}$, except $\mathrm{A}=10 \mu \mathrm{m}$.

Known distribution on Antigonon leptopus - Brunei Daressalam, Hong Kong, India, Israel, Malawi, Simbabwe, South Africa, Taiwan (new record), Thailand (Braun \& Cook 2012, Meeboon \& Takamatsu 2017).

Material examined - Taiwan, Nantou County, Jhushan Township, 23.761280, 120.686424, garden, on Antigonon leptopus, 11 Feb 2019, R. Kirschner \& C.-T. Wang 4700 (PPMH, TNM); Taoyuan City, Zhongli District, Zhongyang West Rd., Section 2, garden, 24.960369, 121.212939, on Antigonon leptopus, 04 Mar 2019, R. Kirschner 4701 (PPMH, TNM) - ITS sequence: GenBank MK685172.

Infection was observed at both localities in the spring with powdery mildew colonies focused on groups of neighbouring leaves so that some twigs appeared moderately to heavily affected whereas leaves of other twigs remained healthy. In summer (June), after a period with heavy rain, no powdery mildew was found at both localities. 


\section{Discussion}

Previously two species of powdery mildews were recorded for A. leptopus, the anamorphic Pseudoidium antigononis (B.S. Reddy, Khalis \& Manohar.) U. Braun \& R.T.A. Cook (= Oidium antigononis B.S. Reddy, Khalis \& Manohar) and the holomorphic Erysiphe polygoni DC. (Braun \& Cook 2012). Based on ITS sequence analysis, however, Meeboon \& Takamatsu (2017) showed that both taxa are conspecific, with E. polygoni having priority. The phylogenetic analysis in Fig. 1 indicated three subgroups within E. polygoni partially correlated with host genera, i.e. Polygonum subgroup, Antigonon plus Muehlenbeckia subgroup and Muehlenbeckia plus Rumex subgroup. The resolution, however, was too poor for allowing a taxonomic conclusion. Comparison of the ITS sequences indicates some variability with up to six different bp, but also a clear barcode gap of at least three bp between the next similar sequences of other species.

Nipple-shaped appressoria were not particularly mentioned in Braun \& Cook (2012) and Shin (2000), but were illustrated in Shin (2000). The two types of conidium germination according to Braun \& Cook (2012) depending on the host and season were found together in the same specimen. The occasional placement of the basal septum of the foot cell up to $12 \mu \mathrm{m}$ distal from the surface of the hypha at the point of branching was not mentioned in previous records of Ps. antigononis and E. polygoni, but illustrated for E. polygoni by Chen et al. (1987) and Hosagoudar \& Agarwal (2009). The taxonomic value of such displaced basal septa of the conidiophores stressed in Braun \& Cook (2012) should not be overemphasized.

This species was recorded for different hosts in and outside the Polygonaceae in Taiwan, with the first records from 1914 by Sawada (Kuo 1998). The host plant, A. leptopus, was recorded for Taiwan also from almost the same time (1916; Wu et al. 2010). This coincidence is, however, considered to be rather based on the overall pioneer stage of science in Taiwan during this era than on a causative connection between introductions of the host and its pathogen during the same time. As discussed for similar cases of pathogen records following the record of host introduction (Kirschner 2015a, b), there was a considerable delay of several decades between the record of the host plant and that of a pathogen on the same plant. In contrast to the cited cases, however, the pathogen was perhaps not introduced but occurred on even earlier introduced or native hosts belonging to the same plant family before also spreading to the introduced plant. At least three insect species have been recorded as feeding on A. leptopus in Taiwan (Wong et al. 1999, Yeh et al. 2007, Ko 2016). Hitherto less than ten pathogenic fungi have been identified to species on $A$. leptopus worldwide (Farr \& Rossman 2019) and no species on this host in Taiwan. As indicated for a powdery mildew on Plumeria rubra L. in Taiwan (Yeh et al. 2019), most likely the pathogenic fungi went unnoticed much longer than their introduced hosts due to the few support for mycological inventories compared to that for botanical and entomological studies.

The invasiveness of some plants might be partially attributed to their strong pathogen defense as suggested for a strong antifungal activity of A. leptopus (Rashmi \& Rajkumar 2011). Our field observation of the powdery mildew, however, indicates that this plant is not less susceptible than other host plants to powdery mildews.

\section{Acknowledgements}

The study was supported by the Experimental Forest, College of Bio-Resources \& Agriculture, National Taiwan University. We thank C. Glatthorn and M. Piepenbring, Goethe University of Frankfurt am Main, for providing literature.

\section{References}

Braun U, Cook RTA. 2012 - Taxonomic manual of the Erysiphales (powdery mildews). CBS Biodiversity Series No. 11. CBS-KNAW Fungal Biodiversity Centre, Utrecht, The Netherlands. 
Burke JM, DiTommaso A. 2011 - Corallita (Antigonon leptopus): Intentional introduction of a plant with documented invasive capability. Invasive Plant Science and Management 4, 265273.

Chen GQ, Han SJ, Lai YQ, Yu YN, Zheng RY. 1987. - Flora Fungorum Sinicorum. Vol. 1, Erysiphales. Beijing: Science Press.

Farr DF, Rossman AY. 2019 - Fungal Databases, U.S. National Fungus Collections, ARS, USDA. Retrieved March 2, 2019, from https://nt.ars-grin.gov/fungaldatabases/

Hosagoudar VB, Agarwal DK. 2009 - Powdery mildews of India - check list. New Delhi.

Kirschner R. 2015a - New records of Pseudocercospora oenotherae and Synchytrium fulgens on the invasive coastal plant Oenothera laciniata in Taiwan. Plant Pathology \& Quarantine 5, 26-33.

Kirschner R. 2015b - First record of Cercospora mikaniicola on the weedy vine Mikania micrantha (Asteraceae) in Taiwan. Fungal Science 30, 55-60.

Meeboon J, Takamatsu S. 2017 - Notes on powdery mildews (Erysiphales) in Thailand IV. Erysiphe species on Malvaceae, Menispermaceae, Moraceae, Nyctaginaceae, Polygonaceae, Solanaceae and Urticaceae. Tropical Plant Pathology 42, 485-494.

Ko CC. 2016 - Aleurodiscus dispersus Russell, 1965. Taieol.tw/pages/92186 (in Chinese)

Kuo KC. 1998 - Checklist of Erysiphaceae from Taiwan. Fungal Science 13, 39-59.

Rashmi S, Rajkumar HG. 2011 - Preliminary phytochemical analysis and in vitro evaluation of antifungal activity of five invasive plant species against Macrophomina phaseolina (Tassi) Goid. International Journal of Plant Research 1(1), 11-15.

Shin HD. 2000 - Erysiphaceae of Korea. Suwon, Korea: National Institute Agricultural Science and Technology.

Wei IC, Kirschner R. 2017 - Two fungicolous anamorphic species of Hypomyces s. lat. from Taiwan. Fungal Science 32, 15-25.

Wong CY, Chen SP, Chou LY. 1999 - Guidebook to scale insects of Taiwan. Taiwan Agricultural Research Institute, Wufeng, Taichung, Taiwan (in Chinese).

Wu SH, Yang TYA, Teng YC, Chang CY et al. 2010 - Insights of the latest naturalized flora of Taiwan: Change in the past eight years. Taiwania 52, 39-159.

Yeh ST, Liao CT, Chen CC, Ko WF. 2007 - The infested area, host plants and damage to Litchi chinensis yield of casuarina moth Lymantria xylina (Lepidoptera: Lymantriidae) in Central Taiwan. Contribution No. 0662 from Taichung DARES, COA. (in Chinese)

Yeh YW, Kirschner R, Lu HF. 2019 - First record of Erysiphe elevata on Plumeria rubra in Taiwan. Plant Disease 103(2), 371. 